\title{
Exercise capacity after His bundle ablation and rate response ventricular pacing for drug refractory chronic atrial fibrillation
}

Eugène $M$ Buys, Norbert $M$ van Hemel, Johannes C Kelder, Carl A P L Ascoop, Pascal F H M van Dessel, Lex Bakema, J Herre Kingma

\begin{abstract}
Objective-To evaluate exercise capacity of patients with chronic atrial fibrillation in whom His bundle ablation followed by ventricular rate response pacing (VVIR) was carried out because of drug refractoriness.

Design-Prospective study.

Patients -25 consecutive patients, all with chronic symptomatic drug refractory atrial fibrillation, underwent His bundle ablation. Before this intervention all patients were on antiarrhythmic drugs to attain acceptable heart rate control and to relief symptoms.
\end{abstract}

Main outcome measures-Exercise capacity, including measurements of $\dot{V}_{2}$, was examined before and after a mean interval of seven months following His bundle ablation.

Results-Exercise capacity after His bundle ablation increased from a mean of 109 (SD 49) W to 118 (46) W $(P<0.002)$, but $\forall \mathrm{O}_{2}$ at peak exercise did not change significantly. Maximum exercise capacity was achieved with a significantly lower maximum driven heart rate than the spontaneous heart rate before ablation.

Conclusions-Exercise capacity of patients who underwent His bundle ablation followed by VVIR pacing remained unchanged or improved during a mean follow up of seven months. Larger patient populations with longer follow up are necessary to examine determinants of improved exercise capacity.

(Heart 1997;77:238-241)

Keywords: chronic atrial fibrillation; His bundle ablation; exercise capacity; VVIR pacing

Departments of Cardiology and Clinical Cardiac Pacing, St Antonius

Hospital, Nieuwegein,

The Netherlands

E M Buys

N M van Hemel

J C Kelder

C A P L Ascoop

P F H M van Dessel

L Bakema

J H Kingma

Correspondence to:

Dr N M van Hemel,

Department of Cardiology,

St Antonius Hospital,

CM Nieuwegein,

CM Nieuwegein,

Accepted for publication

14 November 1996 after His bundle ablation and ventricular rate response pacing (VVIR) for drug refractory chronic atrial fibrillation.

Methods

PATIENTS

This prospective study was performed between August 1993 and September 1994. Patients suffering from symptomatic or incapacitating atrial fibrillation selected for His bundle ablation were included. Exclusions $\mathscr{C}_{\infty}$ were patients showing (1) angina pectoris of 을 more than New York Heart Association (NYHA) class II (IV), (2) aortic or mitral valvar stenosis or incompetence, (3) respiratory diseases interfering with normal oxygen $\vec{\partial}$ uptake, (4) any other abnormality interfering $\vec{\oplus}$ with the capability of performing a bicycle exercise test, and (5) paroxysmal atrial fibrillation.

\section{PROCEDURES}

Exercise testing with oxygen uptake measure- $\frac{D}{D}$ ment was performed to ensure that patients $\vec{\overrightarrow{ }}$ exercised maximally. Before exercise testing 3 both routine spirometry and measurement of haemoglobin were performed, the echocardiographic left ventricular end diastolic dimension (LVEDD) and left atrial dimension were measured using the parasternal long axis, and valve abnormalities were looked for. After His $\underline{3}$ bundle ablation and pacemaker implantation a $\delta$ standard chest $x$ ray was taken to determine $₹$ the position of the pacing lead and to permit $\mathrm{O}$ calculation of the cardiothoracic ratio. For each patient the Quetelet index was obtained by the formula: weight $/(\text { length })^{2}\left(\mathrm{~kg} / \mathrm{m}^{2}\right)$.

\section{Exercise testing with respiratory gas analysis}

The study was performed using an upright $\mathrm{N}$ bicycle ergometer. The mean heart rate during atrial fibrillation was determined by measuring 0 the average heart rate for 15 second intervals. Following a one minute resting period on the bicycle for calibrating the gas exchange data, a continuing graded exercise test was per- $\frac{\vec{D}}{\mathbb{D}}$ formed, starting at $60 \mathrm{~W}$. A programmable, $\frac{9}{8}$ stepwise incremental ramp of $20 \mathrm{~W} / 2 \mathrm{~min} \stackrel{\mathbb{Q}}{2}$ was used with on-line real time gas exchange analysis. Oxygen consumption $\left(\mathrm{V}_{2} 8\right.$ $\mathrm{ml} / \mathrm{min} / \mathrm{kg})$, carbon dioxide production $\left(\mathrm{VCO}_{2}\right.$ 을 $\mathrm{ml} / \mathrm{min} / \mathrm{kg}$ ), and respiratory exchange ratios (RQ) were continuously measured and analysed using an automated breath by breath system (SensorMedics Horizon System 4400TC, SensorMedics Corporation, Anaheim, California, USA). Gas variables were reported 
at 30 second intervals. Peak $\mathrm{Vo}_{2}$ was defined as oxygen consumption at peak exercise calculated as the mean of the values measured during the last 30 seconds of exercise. Therefore oxygen uptake at peak exercise is referred to as peak oxygen uptake (peak $\mathrm{VO}_{2}$ ), not to be confused with $\mathrm{VO}_{2}$ max, defined as the maximum oxygen uptake at any time of the exercise test. Antiarrhythmic drugs used before His bundle ablation remained unchanged in advance of the exercise test. The endpoint of the exercise test was exhaustion in terms of dyspnoea or fatigue.

\section{Pacing treatment and follow up}

After achievement of complete heart block ${ }^{8}$ a permanent pacemaker was implanted using a bipolar lead (Encore 033-301 Telectronics, Lane Cove, Australia) connected to a VVIR pacemaker (Telectronics META III). At discharge, lower pacing rate was set at 70 pacing impulses per minute (ppm) and upper pacing rate varied from $120-150 \mathrm{ppm}$, depending on age and assumed lifestyle. ${ }^{9} \mathrm{~A}$ standard check of the pacemaker function was performed one and six weeks after implantation. Subsequent follow up visits were scheduled every six months and consisted of pacemaker checks, Holter monitoring, and exercise testing.

\section{PACEMAKER CHARACTERISTICS}

The Telectronics Meta III device uses changes in minute ventilation as the sensed variable for adjusting pacing rate. The minute ventilation is derived using $1 \mathrm{~mA}$ current pulses lasting for $15 \mu \mathrm{s}$ at $50 \mathrm{~ms}$ intervals, which are emitted between the proximal lead sensing-pacing ring and the pacemaker casting. The calculated impedance signals vary with the frequency of the respiratory rate and depth of breathing, that is, tidal volume. In the rate response mode the rate adapts to the patient's individual respiratory impedance characteristics. Changes in minute ventilation have been shown to correlate directly with changes in oxygen consumption and hence metabolic demand. ${ }^{10-12}$

Table 1 Baseline clinical characteristics of 25 study patients

\begin{tabular}{|c|c|c|}
\hline Variable & & Value \\
\hline Age, years & & $58(11)^{\star}$ \\
\hline Gender (male/female) & & $14 / 11$ \\
\hline Duration of atrial fibrillation, months & & $79 \cdot 8(34)^{\star}$ \\
\hline \multicolumn{3}{|l|}{ Underlying heart disease } \\
\hline Ischaemic heart disease & & 6 \\
\hline Mitral valve disease & & 5 \\
\hline mitral incompetence grade I (IV) & & 1 \\
\hline mitral valve prolapse & & 2 \\
\hline mitral valve replacement & & 2 \\
\hline Congenital heart disease & & 1 \\
\hline correction ASD (type 2) & & 1 \\
\hline Systemic hypertension & & 4 \\
\hline Lone atrial fibrillation & & 9 \\
\hline \multicolumn{3}{|l|}{ Echocardiographic measurements } \\
\hline Left atrial size & $\mathrm{mm}$ & $49 \cdot 2(6 \cdot 7)^{\star}$ \\
\hline Left ventricular end diastolic diameter & $\mathrm{mm}$ & $49 \cdot 0(5 \cdot 6)^{\star}$ \\
\hline Chest $x$ ray, cardiothoracic ratio & $\%$ & $49(6)^{\star}$ \\
\hline Quetelet index (ref: $<26)$ & $\mathrm{kg} / \mathrm{m}^{2}$ & $25.4(3.5)^{\star}$ \\
\hline Forced expiratory volume/s $\left(\mathrm{FEV}_{1}\right)$ & $\%$ & $73.6(3.8)^{\star}$ \\
\hline \multicolumn{3}{|l|}{ Blood pressure } \\
\hline Systolic & $\mathrm{mm} \mathrm{Hg}$ & $130(26)^{\star}$ \\
\hline Diastolic & $\mathrm{mm} \mathrm{Hg}$ & $81(5)^{\star}$ \\
\hline Haemoglobin & $\mathrm{mmol} / \mathrm{l}$ & $8 \cdot 1(0 \cdot 4)^{\star}$ \\
\hline
\end{tabular}

^Mean (SD).

\section{STATISTICAL ANALYSIS}

Variables with a continuous distribution were expressed as mean values (SD). Differences were compared by means of a two tailed paired $t$ test. For the linear regression a least square estimation after $\log$ transformation of the dependent variable was used.

\section{Results}

PATIENTS

Of 40 patients initially screened for participation in this study, 10 were excluded because of exclusion criteria (1) to (4) and five because of paroxysmal atrial fibrillation. Of the patients included, nine had lone atrial fibrillation (table 1). During a mean interval of 79.8 months before His bundle ablation, a mean of 3.8 different antiarrhythmic drugs was tested, either as single treatment or combined with other antiarrhythmic drugs. Further details of the patients' baseline characteristics are also given in table 1 .

In all patients right sided His bundle ablation was successful at the first procedure. Measurements at pacemaker implantation showed following mean values: ventricular threshold $0.24(0.09) \mathrm{V}$, current $0.64(0.24)$ $\mathrm{mA}$ at pulse width $1.0 \mathrm{~ms}$, and impedance 723 (92) ohms. An intracardiac electrogram could not be recorded in all patients because of lack of sufficient escape rhythm.

\section{RESULTS OF EXERCISE TESTING}

All patients were on antiarrhythmic drugs during the baseline exercise test. The second exercise test with VVIR pacing was performed at a mean interval of seven months after His bundle ablation and all patients were now free of antiarrhythmic drugs. The mean exercise capacity improved significantly from $109 \mathrm{~W}$ before to $118 \mathrm{~W}$ after the intervention $(\mathrm{P}=$ $0.002)$. The mean exercise duration also increased but not significantly $(7 \cdot 2 v 8.2 \mathrm{~min})$. Peak $\mathrm{VO}_{2}$, however, defined as oxygen uptake at peak exercise, did not differ (19.0 $v 18.9$ $\mathrm{ml} / \mathrm{min} / \mathrm{kg}$ ). The gas exchange anaerobic threshold, including the point at which carbon dioxide production increased disproportionally in relation to oxygen consumption and where there was a respiratory exchange ratio of $>1.0$, was reached in all patients. Respiratory quotient as an objective measurement of maximum exercise capacity was adequate and did not differ significantly from before to after the procedure $(1.19 v 1.21)$. The mean maximum heart rate diminished significantly from mean of 153 beats $/ \mathrm{min}$ to a mean of $130 \mathrm{ppm}$ ( $P=$ 0.011 )

After His bundle ablation the mean maximum heart rate was more than $90 \%$ of the programmed upper pacing limit in all patients, whereas 16 patients $(64 \%)$ reached their programmed upper rate pacing limit (table 2). Pacemaker parameters were programmed depending on age and assumed lifestyle. Patients with low exercise capacity before His bundle ablation were set to a lower upper rate pacing limit (120 ppm), in contrast to those with higher exercise capacity (150 ppm). In 
Table 2 Programmed upper rate pacing limit and exercise capacity after His bundle ablation and VVIR pacing. Values are mean (SD)

\begin{tabular}{lcc}
\hline & $\begin{array}{l}\text { Upper rate } \\
120 \text { ppm }\end{array}$ & $\begin{array}{l}\text { Upper rate } \\
150 \text { ppm }\end{array}$ \\
\hline Number of patients & 11 & 14 \\
Number of patients reaching upper rate limit & 5 & 11 \\
Mean maximum heart rate pre-HBA (bpm) & $146 \cdot 4(50 \cdot 0)$ & $159 \cdot 9(34 \cdot 1)$ \\
Mean maximum heart rate post-HBA (ppm) & $112 \cdot 3(18 \cdot 6)$ & $142 \cdot 6(16 \cdot 7)$ \\
Mean exercise capacity pre-HBA (W) & $73 \cdot 6(22 \cdot 0)$ & $137 \cdot 1(47 \cdot 0)$ \\
Mean exercise capacity post-HBA (W) & $81 \cdot 8(24 \cdot 4)$ & $145 \cdot 7(41 \cdot 0)$ \\
Mean age (years) & $65 \cdot 6(7 \cdot 6)$ & $53 \cdot 4(9 \cdot 9)$ \\
\hline
\end{tabular}

Log regression line of the gain of exercise capacity (in percentage) after His bundle ablation compared to baseline ( $X$ axis). Some patients had equal exercise capacity but there was a trend for patients with low exercise capacity to have the most marked

improvement. Two patient started exercise

performance at a level of $40 \mathrm{~W}$.

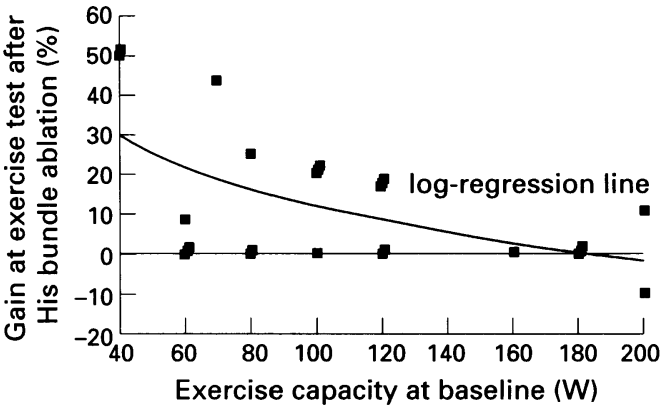

the former group, mean upper rate pacing was $112 \mathrm{ppm}$ and only five patients $(45 \%)$ reached their programmed upper pacing limit (table 2 ), whereas this was the case in the latter group in 11 of 14 patients $(79 \%)$. Fine tuning of the pacemaker parameters in the individual patient can result in a better exercise performance, but it is emphasised that in this study the initial pacemaker settings were not reprogrammed during follow up.

The figure shows the individual changes in exercise capacity after His bundle ablation and VVIR pacing as compared to the baseline condition. In all but one patient the exercise capacity remained stable $(n=12)$ or improved $(n=12)$. Some patients with a low baseline exercise capacity showed a marked improvement after the intervention, whereas other patients had no change at all. A logarithmic line was fitted, which models the trend of the expected improvement of exercise capacity in relation to the baseline exercise capacity.

To identify clinical characteristics possibly related to an improvement in exercise capacity a multivariate analysis of the duration of atrial fibrillation before ablation, peak $\mathrm{VO}_{2}$, the cardiothoracic ratio, and the left ventricular end diastolic diameter was performed. This showed a favourable outcome for those patients having an LVEDD larger than $55 \mathrm{~mm}$ $(P<0.002)$ but this was only observed in four patients.

\section{Discussion}

In this prospective study we examined the exercise capacity before and after His bundle ablation followed by VVIR pacing for drug refractory symptomatic chronic atrial fibrillation, using oxygen consumption as an objective tool. The results of this study show that there was a significant improvement in mean exercise capacity which was most marked in patients with the lowest exercise capacity during drug treated atrial fibrillation before the His bundle ablation (figure). Although the numbers were small, it appears that patients with echocardiographic evidence of an enlarged left ventricular end diastolic diameter (mean $61.7 \mathrm{~mm}$ ) had a greater improvement in exercise capacity.

So far several studies have reported favourable results after His bundle ablation for $\vec{\omega}$ atrial fibrillation in terms of cardiac performance and quality of life. ${ }^{2-6}$ Four studies examined changes in the echocardiographically measured ejection fraction, showing that is a normal baseline ejection fraction remained $\omega_{\infty}^{\infty}$ unaffected after His bundle ablation, whereas 을 a diminished baseline ejection fraction increased. ${ }^{3-6}$ However, in three studies the patients suffered from either chronic or paroxysmal atrial fibrillation, which interferes with the outcome of such studies (table 3$)^{246} \overrightarrow{\mathscr{Q}}$ Several studies have shown that after His bundle ablation the echocardiographic left ventricular end diastolic diameter did not change during follow up (table 3). ${ }^{35613}$ Because improvement in quality of life and the absence of changes of the left ventricular end diastolic $\stackrel{\mathbb{Q}}{\Omega}$ diameter are well established results of His $\overrightarrow{\vec{O}}$ bundle ablation followed by cardiac pacing, these outcomes were not investigated in the present study.

The presented results may be influenced by the behaviour of the sensor of the rate responsive pacing system, the programmed slope of the pacing rates, and the selected lower and 3 upper pacing rates. In all patients the same $\delta$ pacemaker was implanted, and the initial pacemaker parameters were programmed 은 according to age and assumed lifestyle, and were not changed during follow up. We have shown earlier, using questionnaires and exercise testing, that after the initial programming o of this minute ventilation rate responsive pace- $N$ maker, requests for reprogramming during $N$ long term follow up are rare. ${ }^{12}$ Previous studies have reported that after His bundle ablation $\varrho$ the mean maximum achieved driven heart rate $\stackrel{\complement}{\mathscr{C}}$ during exercise varied from 99 to $125 \mathrm{ppm} \stackrel{?}{+}$

Table 3 Several variables at follow up after His bundle ablation

\begin{tabular}{|c|c|c|c|c|c|c|}
\hline Author & Year & No of pts & $A F_{l} b$ & $\begin{array}{l}\text { Follow up } \\
\text { (months) }\end{array}$ & $\begin{array}{l}\text { Mean max } H R \\
\text { after } H B A(p p m)\end{array}$ & $\begin{array}{l}\text { LVEDD after } \\
H B A(\mathrm{~mm})\end{array}$ \\
\hline $\begin{array}{l}\text { Kay }^{2} \\
\text { Heinz }^{5} \\
\text { Twidale }^{4} \\
\text { Brignole }^{3} \\
\text { Edner }^{6} \\
\text { This study }\end{array}$ & $\begin{array}{l}1988 \\
1992 \\
1993 \\
1994 \\
1995\end{array}$ & $\begin{array}{l}12 \\
10 \\
14 \\
23 \\
29 \\
25\end{array}$ & $\begin{array}{l}\text { paroxysmal + chronic } \\
\text { chronic } \\
\text { paroxysmal + chronic } \\
\text { chronic } \\
\text { paroxysmal + chronic } \\
\text { chronic }\end{array}$ & $\begin{array}{l}8 \\
2 \\
1 \cdot 5 \\
3 \\
7 \\
7\end{array}$ & $\begin{array}{l}125 \\
\mathrm{nr} \\
99 \\
105 \\
\mathrm{nr} \\
130\end{array}$ & $\begin{array}{l}\mathrm{nr} \\
\mathrm{NS}^{\star} \\
\mathrm{nr} \\
\mathrm{NS}^{\star} \\
\mathrm{NS}^{\star} \\
\mathrm{nr}\end{array}$ \\
\hline
\end{tabular}

AFib, atrial fibrillation; HBA, His bundle ablation; HR, heart rate; LVEDD, left ventricular end diastolic diameter; nr, not reported. 
(table 3), ${ }^{2-4}$ whereas a mean maximum driven heart rate of $130 \mathrm{ppm}$ was obtained in our study. Further studies are needed to establish the optimal pacing parameters for the individual patient after His bundle ablation for drug refractory atrial fibrillation.

Changes of left ventricular function, and the discontinuation of antiarrhythmic drug treatment, and a general improvement in wellbeing are three possible causes of improved exercise capacity. Improvement of ejection fraction has been associated with improvement of exercise capacity, ${ }^{356}$ but a correlation between $\mathrm{VO}_{2}$ measurement and indices of resting left ventricular function, such as ejection fraction, have not been established. ${ }^{14}$ The measured value of peak $\mathrm{VO}_{2}$, defined as oxygen uptake at maximum exercise, is generally accepted as an estimation of left ventricular function..$^{15} 16$ In our study this value remained unchanged after His bundle ablation and VVIR pacing, and therefore it is unclear whether an improvement of left ventricular function is crucial for better exercise capacity. However, improvement in exercise capacity was associated with a significantly lower driven heart rate compared to the preablation spontaneous heart rate. This finding can be partly explained by insufficiently controlled atrioventricular conduction with antiarrhythmic drugs during atrial fibrillation. In addition, a favourable effect on left ventricular function can be expected after withdrawal of antiarrhythmic drug treatment, eliminating side effects of drugs and possible negative inotropic effects. One might speculate that a more impaired left ventricular function might benefit more from this withdrawal. Finally, one may assume that improved wellbeing can result in higher exercise capacity. Up to now the contribution of any of theseor other-causes to improved exercise capacity remains uncertain and needs further investigation.

\section{CONCLUSION}

This study showed that exercise capacity of patients with VVIR pacing remained unchanged or improved during a mean follow up of seven months. In our view, larger patient populations with longer follow up are necessary to define the determinants of improved exercise capacity.

We thank Mrs Jolanda Willink, Mrs Majdi Mur, and Mr Cees Roeterdink for technical assistance, and Mrs Gerda van der Kuijl for preparing the manuscript.

1 Grogan M, Smith HC, Gersh BJ, Wood DL. Left ventricular dysfunction due to atrial fibrillation in patients initially believed to have idiopathic dilated cardiomyopathy. Am 7 Cardiol 1992;69:1570-3.

2 Kay GN, Bubien RS, Epstein AE, Plump VJ. Effect of catheter ablation of the atrioventricular junction on quality of life and exercise tolerance in paroxysmal atrial fibrillation. Am $\mathcal{F}$ Cardiol 1988;62:741-4

3 Brignole M, Gianfranchi L, Menozzi C, Bottoni N, Bollini $\mathrm{R}$, Lolli $\mathrm{G}$, et al. Influence of atrioventricular junction radiofrequency ablation in patients with chronic atria fibrillation and flutter on quality of life and cardiac performance. Am $\mathcal{F}$ Cardiol 1994;74:242-6.

4 Twidale N, Sutton K, Bartlett L, Dooley A, Winstanley S, Heddle W, et al. Effects on cardiac performance of atrioventricular node catheter ablation using radiofrequency current for drug-

5 Heinz G, Siostrzonek P, Kreiner G, Gossinger H. Improvement in left ventricular systolic function after successfu radiofrequency his bundle ablation for drug refractory,
chronic atrial fibrillation and recurrent atrial flutter. $A m \mathcal{F}$ Cardiol 1992;15:489-92.

6 Edner M, Caidhal K, Bergfeldt L, Darpo B, Edvarsson N, Rosenqvist $M$, et al. Prospective study of left ventricular function after radiofrequency ablation of atrioventricular function in patients with atrial fibrillation. Br Heart $f$ junction in patient

7 Langberg JJ, Chin MC, Rosenqvist M, Cockrell J, Dullet $\mathrm{N}$, van Hare $\mathrm{G}$, et al. Catheter ablation of the atrioventricular junction with radiofrequency. Circulation 1989 80:1527-35

8 Morady F, Calkins H, Langberg JJ, Armstrong WF, de Buitleir M, Rafel El-Atass $\mathrm{R}$, et al. A prospective randomized comparison of direct current and radiofrequency ablation of the atrioventricular junction. $\mathcal{F} \mathrm{Am} \mathrm{Coll}$ Cardiol 1993;21:102-9.

9 Marques K, Hemel NM, Bakema H, Defauw JJAM. Efforts to obtain satisfactory minute ventilation rate responsive pacing. Eur f Cardiac Pacing Electrophysiol 1994:2;81-8.

10 Lau CP, Antonio A, Ward DE, Cam AJ. Reliability of minute ventilation as a param
ing. $P A C E$ 1989;12:321-30.

11 Mond H, Strathmore N, Kertes P, Hunt D, Baker G. Rate responsive pacing using a minute ventilation sensor. PACE 1988:11:1866-74.

12 Abrahamsen AM, Barvik S, Aarsland T, Dickstein K. Rate response cardiac pacing using a minute ventilation sensor. PACE 1993;16:1650-5.

13 Cruz FES, Cheriex EC, Smeets JLRM, Atie J, Peres AK, Penn OCKM, et al. Reversibility of tachycardia induced cardiomyopathy after cure of incessant supraventricular tachycardia. F Am Coll Cardiol 1990;16:739-44.

14 Tjaha IE, Reddy HK, Janicki JS, Weber KT. Evolving role of cardiopulmonary exercise testing in cardiovascular disease. Clin Chest Med 1994;15:271-85.

15 Elborn JS, Stanford CF, Nicholls DP. Reproducibility of cardiopulmonary parameters during exercise in patients with chronic cardiac failure. The need for a preliminary test. Eur Heart $\mathcal{f} 1990 ; 11: 75-81$.

16 Weber KT, Kinasewitz GT, Janicki JS, Fishman AP. Oxygen utilization and ventilation during exercise in Oxygen utilization and ventilation during exercise in
patients with chronic cardiac failure. Circulation 1982;65: patients with 1213 . 